\title{
O estudo do esporte na formação superior em Educação Física: construindo novos horizontes
}

\author{
Fernando Jaime Gonzalez*
}

\begin{abstract}
Resumo: O presente artigo busca refletir sobre o estudo do esporte nos cursos de formação superior de Educação Física. Na primeira parte, o texto discute as dificuldades que historicamente este espaço curricular tem apresentado na formação superior. Em sua segunda seção, o documento examina aspectos considerados fundamentais para uma abordagem mais crítica do estudo do esporte num curso universitário e, finalmente, relata a experiência de organização curricular (ano 2001) no campo do esporte desenvolvida no Curso de Educação Física da Universidade Regional do Noroeste do Estado de Rio Grande do Sul - Unijuí. Palavraschave: Educação Superior, Esporte, Formação Superior
\end{abstract}

A formação superior na área de Educação Física (EF) é um tema longamente discutido desde as mais diferentes perspectivas teóricas e com diversas ênfases quando observados os aspectos analisados. Percebe-se, entretanto, que um dos problemas destacados com freqüência, em muitos destes trabalhos, refere-se à denominada "esportivização" do currículo. Betti e Betti (apud Bracht et al, 2003, p. 41) afirmam sobre o assunto:

O curriculo tradicional-esporlivo enfatiza as chamadas disciplinas "práticas" (especialmente esportivas). O conceito de prática está baseado na execução e demonstração, por parte do graduando, de habilidades técnicas e capacidades físicas (um exemplo são as provas "práticas" em que o aluno deve obter um desempenho físico-técnico mínimo). Há separação entre teoria e prática. Teoria éo conteúdo apresentado em sala de aula (qualquer que seja ele), prática é a atividade na piscina quadra pista, etc A ênfase teorica se da na area biológica psicológica [...] Este modelo iniciou-se ao final da década de 60 e consolidou-se na década de 70, acompanhando a expansão dos cursos superiores em Educação Física no Brasil e a "esportivização" da Educação Física...

Mestre em Ciência do Movimento Humano. Professor da Universidade Regional do Noroeste do Estado do Rio Grande do Sul - Unijuí.

Movimento, Porto Alegre, v. 10, n. 1, p. 213-229, janeiro/abril de 2004 
Esta característica esteve marcada desde os primeiros estudos e se manifestava, entre outros motivos, tanto pelo elevado percentual que as disciplinas que tratam das modalidades esportivas ocupam no currículo, como pela tematização que se faz do esporte nesses componentes curriculares.

Pelo menos uma dessas características dos currículos, entretanto, vem mudando, aquela vinculada à dimensão quantitativa (Da Costa, 1999). A ênfase nas disciplinas esportivas vem sendo substituída por disciplinas que tratam de outras manifestações da cultura corporal de movimento, como também por disciplinas denominadas de acadêmicas (oriundas tanto das Ciências Humanas e Sociais como do campo das Ciências Naturais). As disciplinas esportivas, contudo, não mudaram quanto ao tratamento do conteúdo. Assim, a aparente redução na esportivização passa mais por uma questão de quantidade que por uma transformação qualitativa no entendimento do fenômeno esportivo no campo do ensino superior em EF.

As afirmações precedentes ficam evidentes quando revisamos estudos dos últimos quinze anos que discutem o tratamento das disciplinas esportivas nos cursos de formação profissional. No caso Oliveira $^{1}$ (1989) apresenta um profundo estudo sobre as disciplinas práticas do curso de EF da Universidade Estadual de Maringá, no qual conclui que o conjunto de procedimentos didático-pedagógicos que organizam as aulas "reproduzem e reforçam os aspectos sociais controladores da ordem opressora instituída" (p.252); que "o aprendizado e a prática, pelos participantes, do desporto institucionalizado são tidos como funções fundamentais destas disciplinas" (p. 252), resultando na cobrança do gesto técnico como processo de avaliação; que os procedimentos pedagógicometodológicos nas aulas "caracterizam-se preferencialmente por serem de tipo fechado e sem condições de decisão para os alunos, restando a estes a função de estarem presentes e obedecerem ao plano e às ordens do professor" (p. 253); que as práticas de ensino de estagiários e egressos são um claro reflexo dos procedimentos evidenciados nas disciplinas práticas do curso, o que "acaba por resultar em uma prática, por parte de estagiários e egressos, reproductivista, comodista, submissa, ingênua e com fim em si mesma" (p.253).

1 As disciplinas citadas como "práticas" são as seguintes: basquetebol, voleibol, handebol, atletismo, natação, futebol, ginástica masculina, ginástica feminina, ginástica rítmica feminina e masculina, ginástica artística feminina e ginástica artística masculina (Oliveira, 1989, p. 235)

Movimento, Porto Alegre, v. 10, n. 1, p. 213-229, janeiro/abril de 2004 
Tani $(\mathrm{s} / \mathrm{d})$ também é enfático em afirmar que o conjunto de disciplinas relativas às diversas manifestações da cultura corporal de movimento (esporte, ginástica, jogo, dança) se limita basicamente à prática motora que caracteriza o próprio fenômeno, em lugar de conhecimentos sobre o mesmo. O que se observa, segundo o autor citado, é apenas a "transmissão do patrimônio cultural historicamente acumulado", orientada simplesmente pela "experiência, intuição e senso comum" do professor ${ }^{2}$ da disciplina universitária. Este autor, alias, é eloqüente em relação a este aspecto, quando entende que, da forma como as disciplinas de orientação às atividades vêm sendo trabalhadas, "é difícil diferenciar, por exemplo, uma aula prática de voleibol desenvolvida no curso de preparação profissional em escolas de EF e numa disciplina curricular de EF em escolas de $1^{\circ}$ e $2^{\circ}$ graus" (p.21).

Exemplos da leitura de Tani $(\mathrm{s} / \mathrm{d})$ sobre as disciplinas práticas podem ser encontrados nas observações que Molina Neto (1995) faz sobre o tratamento da disciplina "Futebol" na graduação de professores de $\mathrm{EF}$, o qual se reduz à prática dos "fundamentos" do esporte, ao estudo das regras nos dias que não era possível a prática no campo (por exemplo, em dias de chuva), para logo aprender a distribuir os jogadores no campo e jogar segundo as normas oficiais. Também é possível observar esta lógica de tratamento das disciplinas esportivas no estudo de Pirolo (1997). Este último autor realizou um estudo com os professores da disciplina acadêmica "Voleibol" em seis universidades do Paraná, concluindo que a maioria dos professores tinha um entendimento de educação caracterizada pela idéia de transmissão de informações e regras sociais para o educando adaptar-se ao sistema social vigente; uma imagem de EF marcada por idéias higienistas e pedagogicistas; um conceito de competência técnicoprofissional equivalente ao conhecimento das atividades desportivas (saber-fazer) e de seqüências pedagógicas para o ensino dos fundamentos técnicos e táticos do esporte; e uma representação de competência política análoga à capacidade para conseguir as condições necessárias à massificação desportiva no país (p.194).

São evidentes as semelhanças entre a conclusões de Oliveira (1989) e Pirolo (1997), como também o são com outras descrições encontradas em Daolio (1998) e Castellani Filho (1998).

2 Aliás, o perfil do professor universitário das disciplinas esportivas é questionado por vários autores (Daolio,1998; Melo, M. at al, 2002; Pirolo, 1997; Terra, 1997;).

Movimento, Porto Alegre, v. 10, n. 1, p. 213-229, janeiro/abril de 2004 
Particularmente estes dois últimos autores, em seus respectivos trabalhos, descrevem que no momento de sua formação profissional (década de 70) as disciplinas esportivas em muito se pareciam àquelas que foram descritas anteriormente e que conseqüentemente poucos elementos puderam oferecer para entender o esporte fora da dimensão técnica. Isso não seria tão alarmante se não fosse o fato de que passados 30 anos, a maioria dos cursos de Educação Física continua trabalhando dessa mesma forma. Daolio (1998), nesta linha, é claro quando afirma:

a formação atual de grande parte dos profissionais de educação fisica, que se dá na maioria dos mais de 150 cursos superiores espalhados pelo Brasil ainda não conseguem tratar o esporte nas suas dimensões históricas, culturais,sociológicas, econômicas, como fenômeno de marketing, etc. A grande quantidade de horas nas disciplinas que tratam o esporte nos cursos de formação profissional em educação fisica ainda é destinado aos aspectos técnicos das modalidades, fazendo que os alunos, futuros professores, pratiquem os fundamentos esportivos na duvidosa premissa de que basta aos alunos saberem fazer para saberem ensinar futuramente (p. 111-112).

Na mesma linha, Castellani Filho (1998) lamenta que quase nada mudou desde sua Graduação no que respeita ao tratamento das disciplinas esportivas. Talvez, como o autor afirma em relação à disciplina acadêmica/modalidade "futebol", a única mudança, na maioria dos cursos de Graduação, é que as alunas, diferentemente de quando ele estudou, "compartilham com seus colegas a pobreza intelectual das aulas de futebol que continuam não dando conta de estudarem este fenômeno sociocultural de outra perspectiva que não seja a técnico-táctica" (p. 44).

Não são diferentes as percepções de Terra (1997) e Ferreira (1998), que afirmam ser evidente que a forma de trabalhar as disciplinas esportivas "vem apresentando resultados insatisfatórios, além da falta de propostas no sentido de promover uma formação técnica, científica e filosófica competente, com vistas a um profissional efetivamente compromissado com a construção de uma cidadania crítica, responsável e autônoma" (Terra, 1997 p.208), e "que muitas disciplinas esportivas mantêm ainda um cunho téc-nicodesportivo sem qualquer fundamentação sociopedagógica crítica, indicando ausência de reflexão, sobre a autonomia e identidade pedagógicas da EF" (Ferreira, 1998, p.109). Pires e Neves (2002) fazem uma leitura muito similar, entendendo também que, no campo destas disciplinas, "ainda predominam os processo pedagógicos restritos à competência objetiva ou técnica" (p. 71).

Movimento, Porto Alegre, v. 10, n. 1, p. 213-229, janeiro/abril de 2004 
Assim, se existe alguma coincidência entre os diferentes autores que estudam esta problemática, é que uma formação no campo do esporte, pautada pela lógica descrita, instrumentaliza muito pouco, os alunos para desenvolverem competências tanto sociais como técnicas que possam ir além da reprodução. $\mathrm{O}$ limite concreto de pautar o ensino dos esportes exclusivamente na dimensão técnico-táticoregulamentar, ainda que a importância deste conhecimento não seja desconsiderada, se coloca na impossibilidade de oportunizar ao futuro professor novas significações do fenômeno esportivo, o que é definido por Pires e Neves (2002) como uma "semicultura esportiva". Nesta linha, Daolio (1998) também afirma que um programa de graduação que insista neste modelo técnico-esportivo "não estará formando profissionais capazes de considerar a contínua significação e ressignificação das modalidades esportivas por parte de diversos grupos 'humanos ao longo do tempo", ou seja, "não estará priorizando a discussão do esporte como cultura humana" (p. 112).

Com estas preocupações, alguns intelectuais da área têm proposto inovações como também desenvolvido experiências no sentido de superar as práticas tradicionais (Daolio, 1998; Ferreira, 1998; Molina Neto, 1995; Pires e Neves, 2002; Terra, 1997). No conjunto destas propostas superadoras é possível identificar alguns princípios de intervenção didático-pedagógicos similares para o ensino das disciplinas esportivas nas universidades. Entre outros, poderíamos apontar: a) a lógica de centrar a formação dos futuros professores no diálogo e na reflexão sobre o fenômeno esportivo, seu processo de ensino e sua implicação na formação dos sujeitos; b) procurar que os acadêmicos compreendam o esporte como uma construção cultural, social e historicamente localizada, e, por isso, passível de transformação; c) dar centralidade à compreensão do processo de ensino-aprendizagem como um ato político e, necessariamente, engajado num projeto social (por ação ou por omissão) e não como uma intervenção neutra e asséptica.

Por outro lado, é interessante observar que, do conjunto de trabalhos mencionados, só Daolio (1998) desafia a pensar um currículo que organize o estudo da "pedagogia do esporte" em blocos de modalidades - coletivas, aquáticas, aquelas que necessitam de implementos ou materiais - a qual apresentaria vantagens pela possibilidade de estabelecer uma linha de atuação conjunta no tratamento pedagógico dos diferentes tipos de es-

Movimento, Porto Alegre, v. 10, n. 1, p. 213-229, janeiro/abril de 2004 
porte. Os outros estudos se caracterizam por trabalhar, ainda que de forma inovadora, apenas dentro de uma disciplina, e não na perspectiva de transformar o campo do estudo do esporte como um todo, o que segundo nosso ponto de vista limita, e muito, o estudo do fenômeno sob um novo conceito.

\section{Idéias básicas do estudo do esporte nos cursos superiores de formação profissional em EF}

Entendemos que o esporte, no currículo de um curso de formação profissional em EF, precisa ser assumido como um campo de estudo, ou seja, um espaço da realidade que deve ser melhor explicado e compreendido para poder interagir com ele a partir da especificidade profissional. Assim, algumas das perguntas que se colocam são: Qual é essa especificidade profissional? O que faz um profissional de EF em relação ao esporte? Concebemos, inicialmente, que a atuação profissional em EF, no espaço do esporte, pauta-se pela meta de "oportunizar a seus alunos a reconstrução inteligente, prazerosa, competente e contextualizada, num ambiente de aula crítico e sensível" (GONZALEZ, 1999, p. 519) desta parte da cultura corporal de movimento.

Sob essa perspectiva, se orientamos a intervenção profissional basicamente por este propósito, necessariamente também a formação deveria pautar-se por esta intenção, o que, conseqüentemente, faria emergir a obrigação de conhecer esse complexo processo a partir desse ponto de vista. Para tanto, é necessário partir de uma determinada representação (sempre provisória e passível de modificações) que nos permita a leitura do fenômeno com o qual interagimos. Como lembra Fensterseifer (1999), a teoria, no campo da EF e, conseqüentemente, no processo de mediação que caracteriza o ensino dos esportes, "é um 'arsenal' discursivo e instrumental construído historicamente e sempre por construir" (p.180). Dominar esse "arsenal", ampliá-lo e modificá-lo é tarefa que se impõe a esta área de intervenção.

Qual é, então, o fenômeno que se necessita melhor compreender? Entendemos que seja o fenômeno do processo de mediação que o profissional de EF realiza para propiciar as condições necessárias que permitam que os sujeitos se introduzam e se integrem também $^{3}$ ao esporte, formando os cidadãos que vão produ-

Movimento, Porto Alegre, v. 10, n. 1, p. 213-229, janeiro/abril de 2004 
zi-lo, reproduzi-lo, transformá-lo, instrumentalizando-os para usufruir a prática esportiva em beneficio de sua qualidade de vida, ou seja, propiciar que os alunos sejam praticantes lúcidos e ativos, que incorporem o esporte em sua vida para dele tirar o melhor proveito possível (Betti, 1998, p. 19).

Partindo dessa idéia nos deparamos com diversos elementos que atravessam esse processo de mediação, que, necessariamente, devem ser melhor compreendidos para poder intervir de uma forma mais lúcida do ponto de vista político, e eficiente do ponto de vista técnico. Quais são as dimensões que hoje conseguimos identificar? Entendemos como elementos que afetam intimamente o processo de mediação: a) o próprio fenômeno cultural objeto de conhecimento: $o$ esporte; b) os sujeitos da aprendizagem; c) os procedimentos de organização e condução dos processos de mediação; d) os valores sociais que inevitavelmente atravessam o processo de mediação, orientam os programas de ensino e as relações intersujetivas que acontecem entre os membros do grupo que compartilha esse processo; e) as instituições em que se dá este processo de mediação, ou seja, as organizações sociais que instituem e dão espaço para o ensino do esporte e os diferentes atores que participam da organização; f) o contexto histórico-social que envolve tanto o fenômeno esportivo como os outros elementos já descritos. Isso significa que um espaço curricular que estuda o esporte num programa de formação superior em EF deveria oportunizar a seus acadêmicos o conhecimento sobre este conjunto de aspectos. De outra forma, a compreensão do processo de ensino-aprendizagem do esporte seria fortemente comprometida.

\section{A experiência do curso de EF da Unijuí na estruturação e desenvolvimento do campo de estudo do esporte}

De acordo com as conclusões expressas passaremos agora a expor, de forma concisa, a estrutura do campo de estudo do esporte do Curso de EF da Universidade Regional do Noroeste do

\footnotetext{
3 Entendemos que este propósito se estende a todas as manifestações da cultura corporal; porém, como este artigo se refere particularmente ao esporte, restringimos a análise a este aspecto.
}

Movimento, Porto Alegre, v. 10, n. 1, p. 213-229, janeiro/abril de 2004 
Estado de Rio Grande do Sul, Unijuí, (CEFU). A descrição se refere ao novo currículo do Curso de EF, que entrou em vigência em 2001 em substituição ao currículo em vigor desde 1991.

Quando da elaboração do projeto identificou-se uma série de núcleos fundamentais para a construção do novo currículo, como "a temática da corporeidade, sobretudo de ordem ética e estética; as questões do corpo-movimento-saúde-qualidade de vida; a centralidade da ascensão da cultura corporal esportiva e as políticas públicas de lazer; os quais serviram como ponto de sustentação às alterações do referido projeto" (CEFU, 2000 p.6). Estas temáticas balizaram uma série de posicionamentos críticos e traduziram-se em formas específicas de abordar as referidas questões e tratar os diversos campos de conhecimento.

Particularmente no campo do estudo dos esportes o projeto político-pedagógico do CEFU sustenta:

que a formação acadêmica no processo ensino-aprendizagem do esporte tem compromisso de ir além da instrumentalização técnica, o que tem sido historicamente caracterizado como ensino do esporte na universidade. É imprescindivel a formação pedagógica mais ampliada para entender o esporte na sua complexidade, numa perspectiva crítica, como um elemento emancipatório, como espaço humanizado (CEFU, 2000, p. 8).

Assim, com base neste entendimento e pautado ademais pelo processo de avaliação da forma como se efetivava o ensino dos esportes no currículo de 1991, nas propostas inovadoras dentro dos diferentes componentes curriculares do próprio curso, que encontravam limites para seu desenvolvimento na anterior organização curricular, e em trabalhos sobre formas superadoras de organizar o estudo do esporte na universidade, o coletivo de professores do CEFU idealizou e desenvolveu a atual proposta de estudo do campo dos esportes para a formação de profissionais de EF.

Resumidamente, a proposta embasou-se em cinco elementos. Primeiro, por organizar a tematização do esporte como um campo de estudo e não como uma justaposição de disciplinas/ modalidades esportivas isoladas. Segundo, por deslocar o eixo de discussão exclusivamente das modalidades esportivas em direção aos elementos comuns no processo de mediação descrito anteriormente. Terceiro, por centrar os estudos fortemente nos elementos universais do esporte (Parlebas, 1988 e 2001) e não nos elementos particu-

lares das modalidades. Quarto, por utili-

Movimento, Porto Alegre, v. 10, n. 1, p. 213-229, janeiro/abril de 2004 
zar, como estratégias fundamentais na formação a pesquisa, as experiências de prática de ensino e as práticas motoras pautadas pela idéia de laboratório de aprendizagem (Gonzalez, 1999; Tani, s/d) e não por práticas motoras orientadas para a formação do praticantereprodutor. Quinto, por formar o futuro professor para lidar com um fenômeno social extremamente dinâmico, diverso, complexo e contraditório e não instrumentalizá-lo exclusivamente para trabalhar com um número restrito de modalidades ${ }^{4}$ como se fossem fixas e imutáveis. Isto significa que o futuro professor necessita entender de esporte e do processo de mediação e não exclusivamente de alguns elementos (freqüentemente só de fundamentos e regras) de $n$ modalidades esportivas.

O campo de estudo dos esportes se organiza no atual projeto em onze, componentes curriculares, distribuídos do primeiro ao quinto semestres, acumulando um total de 32 créditos ou 480 horas, e dividido nos seguintes temas de estudos: a) estrutura dos esportes; b) metodologia do ensino; c) pedagogia do esporte; e) etapas da formação esportiva; f) planejamento da formação esportiva; g) elementos psicossociais e h) elementos hostórico-sociais.

Nesta nova estrutura o conteúdo dos componentes centra-se sobre os elementos ou dimensões comuns ao processo de mediação, o que permite, além de organizar o conjunto de disciplinas como área de conhecimento, maior aprofundamento sobre um determinado assunto, diminuindo sensivelmente a reiteração de vários temas abordados, de forma superficial, pelas diferentes disciplinas que tratam, de forma isolada, das modalidades esportivas ${ }^{5}$ (exemplo - metodologia de ensino, valores implicados na formação esportiva, etapas da formacão esportiva, elementos ou componentes do desempenho esportivo, competição infantil, entre muitos outros). No diagnóstico realizado sobre o ensino das modalidades esportivas no currículo de 1991, no CEFU, ficou evidente que todas as disciplinas/modalidades tratavam de diversos elementos em comum, porém nenhuma delas conseguia aprofundar qualquer dos assuntos.

4 Basquetebol, voleibol, handebol, atletismo, natação, futebol, futsal, ginástica rítmica e ginástica artística, como acontece em muitos dos cursos de formação profissional (DA COSTA, 1999).

5 Conferir comentários a respeito, especificamente sobre os esportes coletivos, em Farias Júnior (1993, p.236).

Movimento, Porto Alegre, v. 10, n. 1, p. 213-229, janeiro/abril de 2004 
Cada um dos componentes do novo currículo, no momento em que tematiza os elementos de sua responsabilidade, o faz utilizando como laboratório de aprendizagem (Gonzalez, 1999) modalidades esportivas que servem como exemplo concreto dos assuntos estudados. Estas modalidades são intrumentalizadas de tal forma que permitam (e exijam) estabelecer vínculos com o conjunto das modalidades esportivas (com base na lógica interna e externa das mesmas), possibilitando aos alunos abstraírem esses conceitos e utilizá-los em qualquer prática esportiva, particularmente naquelas que não serão abordadas na universidade e/ou ainda não foram "inventadas" (Figura 1). Assim, por exemplo, os componentes curriculares que estudam a estrutura e dinâmica dos esportes (Esporte I e II) utilizam como modalidade no laboratório o handebol porém, apenas como um caso concreto que permite observar como se manifestam os diferentes elementos que são comuns aos esportes. ${ }^{6}$

As modalidades selecionadas para serem usadas nos laboratórios de ensino-aprendizagem das disciplinas foram escolhidas a partir da análise das lógicas internas e externas das mesmas (Parlebas, 1988 e 2001). Procurou-se assim, que a lógica da modalidade referenciada permita uma abordagem mais consistente dos conteúdos programáticos do componente curricular. Por exemplo, entendeu-se que o estudo sobre as dimensões só histórico-sociais do esporte e suas implicações no processo de mediação torna-se mais rico quando remete ao futebol como mo-

\footnotetext{
6 Conteúdos de Esporte I: Identificação do esporte no campo da cultura corporal de movimento (conceitos iniciais)

Esporte e cultura.

- Esporte e senso comum.

Estruturas dos esportes.

- Classificação dos esportes.

- Classificação das habilidades motoras.

- Os mecanismos internos de organização e regulação da ação motora (mecanis mos de processamento da informação).

As regras esportivas (aspectos formais, desenvolvimento do jogo e meta-regras).

Elementos do desempenho esportivo.

- Técnica esportiva, habilidade técnica, tática individual e intenção tática.

- Introdução a combinações táticas, sistema de jogo, estratégias, capacidades físicas e capacidades volitivas.

- Os subpapéis nos jogos esportivos coletivos de invasão.
}

Movimento, Porto Alegre, v. 10, n. 1, p. 213-229, janeiro/abril de 2004 
dalidade de laboratório, devido a seu significado social para o brasileiro; para estudar as dimensões psicossociais, particularmente aquelas referidas a temas como competição infantil, intervenção do dirigente esportivo no processo de mediação, expectativas dos pais, entre outras, foi selecionada a modalidade futsal, motivada pela organização e desenvolvimento que essa prática esportiva apresenta na região onde se localiza o CEFU; por sua vez, o atletismo foi referenciado, pela sua lógica interna, para estudar a metodologia do ensino dos esportes em que não há interação com o adversário (GONZALEZ, 2001). Isso, entretanto, não significa que seja impossível pensar outras modalidades para o laboratório de ensinoaprendizagem. No futuro, segundo as transformações do dinâmico e diversificado mundo esportivo, ou em outro projeto curricular que adote uma lógica similar ao nosso modelo, as modalidades utilizadas como referência poderão ser outras.

\section{Esporte II:}

Elementos universais do desempenho esportivo nas diversas modalidades.

A análise em "vivo".dos processos internos de regulação da ação motora.

- O pensamento tático e a regulação da conduta nos jogos esportivos.

Intenções técnico-táticas avançadas (1 contra 1).

- A antecipação complexa nos jogos esportivos.

Combinações táticas.

- Combinações táticas elementares, simples, básicas, complexas e situações especiais. Sistemas de jogo.

- Ofensivo (posicionai, transição e livre).

- Defensivo (zona, individual, combinado, misto, pressão).

- Transição (fases do contra-ataque e do retorno defensivo).

A estratégia esportiva: conceitos básicos e a relação com os outros elementos do desempenho esportivo.

A ação esportiva como manifestação dos diferentes elementos do desempenho em diversas modalidades esportivas.

Introdução ao programa-marco de aproximação progressiva aos esportes coletivos em que há interação com o adversário ou de cooperação e oposição. Avaliação dos diferentes tipos de aprendizes, esportes e situações que influenciam o planejamento de experiências de aprendizagem eficientes, tomando como referência as etapas do programa-marco (handebol).

Movimento, Porto Alegre, v. 10, n. 1, p. 213-229, janeiro/abril de 2004 
Figura 1. Denominação e ementas dos componentes curriculares do campo do estudo do esporte (CEFU, 2000, p.28)

\begin{tabular}{|c|c|}
\hline $\begin{array}{l}\text { Componente } \\
\text { curricular }\end{array}$ & Ementa \\
\hline $\begin{array}{l}\text { Esporte I: Estrutura } \\
\text { dos Esportes I }\end{array}$ & $\begin{array}{l}\text { Visa desenvolver conhecimento sobre os elementos universais da } \\
\text { lógica interna dos esportes e as suas dimensōes estrutural e } \\
\text { funcional, referenciando a modalidade esportiva handeblo }\end{array}$ \\
\hline $\begin{array}{l}\text { Esporte II: Estrutura } \\
\text { dos Esportes II }\end{array}$ & $\begin{array}{l}\text { Estuda e investiga sobre a ação de jogo e os elementos universais } \\
\text { dos esportes: tática e técnica individuais, tática coletiva e sistema } \\
\text { de jogo, referenciando a modalidade esportiva handebol }\end{array}$ \\
\hline $\begin{array}{l}\text { Esporte III: Etapas da } \\
\text { Formação Esportiva }\end{array}$ & $\begin{array}{l}\text { Estuda as fases e etapas da formaçáo esportiva, evolução da } \\
\text { competência motora, desenvolvimento das capacidades fisicas e } \\
\text { sua relaçáo com a aprendizagem esportiva, referenciando a } \\
\text { modalidade esportiva atletismo - provas de pista. }\end{array}$ \\
\hline $\begin{array}{l}\text { Esporte IV: } \\
\text { Metodologia } \\
\text { do Ensino dos } \\
\text { Esportes I }\end{array}$ & $\begin{array}{l}\text { Estuda e pesquisa o conhecimento implicado nos jogos } \\
\text { desportivos coletivos, seu vinculo com as dimensôes estrutural e } \\
\text { funcional, aprendizagem motora, desenvolvimento do } \\
\text { pensamento tático e a disponibilidade técnica/coordenativa, } \\
\text { referenciando a modalidade esportiva basquetebol }\end{array}$ \\
\hline $\begin{array}{l}\text { Esporte V: } \\
\text { Metodologia } \\
\text { do Ensino dos } \\
\text { Esportes II }\end{array}$ & $\begin{array}{l}\text { Estuda e pesquisa os modelos de intervenção pedagógica para o } \\
\text { ensino dos jogos desportivos coletivos e a marco organizativo, } \\
\text { planejamento e estruturaçấo da formaçâo esportiva - objetivos e } \\
\text { conteúdos por etapas - referenciando a modalidade esportiva } \\
\text { basquetebol. }\end{array}$ \\
\hline $\begin{array}{l}\text { Esporte VI: } \\
\text { Metodologia } \\
\text { do Ensino dos } \\
\text { Esportes III }\end{array}$ & $\begin{array}{l}\text { Visa estudar o ensino dos esportes em que náo há interaçâo com } \\
\text { o adversário, abordando as teorias de aprendizagem motora } \\
\text { (elementos coordenativos) com ênfase na teoria do esquema } \\
\text { motor geral e na hipótese de prática variável, referenciando a } \\
\text { modalidade esportiva atletismo - provas de campo. }\end{array}$ \\
\hline $\begin{array}{l}\text { Esporte VII: Pedagogia } \\
\text { do Esporte I }\end{array}$ & $\begin{array}{l}\text { Estuda as dimensỏes educativas do esporte e seus vinculos com } \\
\text { as correntes do pensamento pedagógico brasileiro, referenciando } \\
\text { a modalidade esportiva voleibol. }\end{array}$ \\
\hline $\begin{array}{l}\text { Esporte VIII: } \\
\text { Pedagogia } \\
\text { do Esporte II }\end{array}$ & $\begin{array}{l}\text { Estuda e pesquisa sobre o processo ensino-aprendizagem e a } \\
\text { prática do esporte como campo de introjeçăo de valores e } \\
\text { desenvolvimento de competências sociais, afetivas e cognitivas, } \\
\text { referenciando a modalidade esportiva voleibol. }\end{array}$ \\
\hline $\begin{array}{l}\text { Esporte IX: } \\
\text { Planejamento da } \\
\text { Formaçâa Esportiva }\end{array}$ & $\begin{array}{l}\text { Discute os fundamentos e bases para a formulação de um } \\
\text { projeto de formaçăa esportiva, referenciando a modalidade } \\
\text { esportiva futebol. }\end{array}$ \\
\hline $\begin{array}{l}\text { Esporte X: Dimensôes } \\
\text { Psicossociais do } \\
\text { Esporte }\end{array}$ & $\begin{array}{l}\text { Estuda e pesquisa os itinerários esportivos, os aspectos } \\
\text { psicossociais do ambiente esportivo, tanto nos processos de } \\
\text { ensino-aprendizagem-treino como na competiçấo esportiva } \\
\text { infantil, referenciando a modalidade esportiva futsal. }\end{array}$ \\
\hline $\begin{array}{l}\text { Esporte XI: Dimensōes } \\
\text { Histórico-sociais do } \\
\text { Esporte }\end{array}$ & $\begin{array}{l}\text { Estuda e pesquisa o desenvolvimento histórico-social do esporte, } \\
\text { sua mercantilizaçăo, a relaçáo com a ideologia e questôes étnicas } \\
\text { e de gênero, referenciando a modalidade esportiva futebol. }\end{array}$ \\
\hline
\end{tabular}

Movimento, Porto Alegre, v. 10, n. 1, p. 213-229, janeiro/abril de 2004 


\section{Considerações finais... potencialidades, limites e desafios}

Entendemos que este novo modelo de estudo do esporte apresenta uma série de potencialidades. Entre outras, permite-nos trabalhar com o entendimento de que o esporte é um fenômeno hitórico-social e que o processo de mediação é complexo, fazendo dessa intervenção um processo único e impossível de ser tratado apenas a partir de uma racionalidade técnica (Schõn, 2000, p.17). A dimensão heurística desta nova proposta permite pensar o estudo do esporte para além dos modelos caracterizados pela justaposição de "n" modalidades esportivas.

Um dos maiores riscos na implementação deste projeto, porém, é a possibilidade de entender que apenas um novo modelo curricular seja suficiente para mudar o tratamento do esporte e não uma transformação radical do processo de ensino-aprendizagem/estudo dos mesmos nas universidades. Dito de outra forma, apenas a proposição de um novo modelo não garante novas práticas, só um esforço coletivo de ressignificação dentro desta perspectiva proporcionará uma expectativa real de mudança. Existe sempre a possibilidade de acreditar que foi apenas um "aggiornamento", uma mudança só de nomenclatura ou uma re-alocação de disciplinas dentro da semestralidade. É bastante simples retornar à rotina, particularmente quando não se tem uma outra receita a seguir.

Um limite claro para o funcionamento deste novo modelo é a produção teórica no campo do esporte. Por um lado, temos as obras da "própria área", caracterizadas pelo abundante número dos denominados "manuais" de exercícios, uma das manifestações mais concretas da pobreza intelectual na área de esporte, que reduzem o ensino do esporte a um conjunto de tarefas para "aplicar" nas aulas e reforçam fortemente a idéia simplificada de ensino dos esportes com a qual o aluno chega à universidade (Graça, 2000). Por outro lado, uma vasta produção na área das Ciências Humanas e Sociais problematiza o esporte a partir de suas "ciências mães" ou disciplinas de origem sem ter como centralidade da reflexão o processo de mediação (Bracht, 1999). Outro limite concreto situa-se na forte tradição característica dos processos de ensino-aprendizagem neste campo, profundamente vinculada a práticas reprodutivistas e de baixíssimo nível reflexivo (Scaglia,1999).

Movimento, Porto Alegre, v. 10, n. 1, p. 213-229, janeiro/abril de 2004 
Acreditamos que o principal desafio é avançar... Isso significa radicalizar o modelo, fortalecer cada vez mais esta área de estudo, centrando-a sobre o processo de mediação no esporte. Daí deve resultar um avanço no campo da pesquisa, de cada urna das dimensões que fazem parte do fenômeno, tendo a intervenção como eixo das decisões sobre o que estudar. Pensar, desenhar, implantar e avaliar novas estratégias de formação profissional, coerentes com este novo entendimento de estudar o esporte, o que compreende desde construir novos dispositivos até novos materiais didáticos. Outro grande desafio passa pela formação dos professores universitários na área do esporte, para o que deveremos cada vez mais nos empenhar na construção de uma nova identidade acadêmica, capaz de superar a idéia de professor universitário/técnico-esportivo da modalidade x ou y. El estudio del deporte en la enseñanza superior en
Educación Física: construyendo nuevos horizontes.
Resumen: El presente artículo procura reflexionar sobre el
estudio del deporte en la carrera de formación superior en
Educación Física. En la primera parte, el texto discute las
dificultades que históricamente este espacio curricular ha
presentado en laformación superior. En la segunda parte,
el documento examina aspectos considerados
fundamentales para un abordaje mas crítico del estudio del
deporte en un curso universitario y, finalmente, relata la
experiencia de organización curricular (año 2001) en el
campo del deporte desarrollada en la Carrera de
Educación Física de la Universidad Regional del Noroeste
del Estado do Rio Grande do Sul -Unijuí.

Palabras-clave: Educación Superior, Deporte, Formación Superior.

Movimento, Porto Alegre, v. 10, n. 1, p. 213-229, janeiro/abril de 2004 
The study of sports in undergraduation in Physical Education: building up new horizons Abstract: The present paper intents to reflect on the study of sports in undergraduation courses in Physical Education. In the first part, the text discusses the difficulties that this curricular area has historically presented in undergraduation level. In its second section, the document examines aspects that are believed to be fundamental to a more critical approach to the study of sports in a course at university, and, finally, it reports the experience of organizing the curriculum (in 2001) of the sports field, which was developed in the course of Physical Education of the Universidade Regional do Noroeste do Estado do Rio Grande do Sul- Unijuí. Keywords: Higher Education, Sport, Higher Formation.

\section{Referências}

BETTI, M. A janela de vidro: esporte, televisão e educação física. São Paulo: Papirus, 1998.

BRACHT V. Educação Física e Esportes: intervenção e conhecimento. In: Revista da Educação Física/UEM 10 (1): 95-100, 1999.

BRACHT; V., et aL. Pesquisa em ação: educação física na escola, intervenção e conhecimento. ljuí: Unijuí, 2003.

CASTELLANI FILHO, L. Política educacional e educação física. SP: Autores Associados, 1998.

CURSO DE EDUCAÇÃo FísICA - Unijuí. Projeto do Curso de Educação Física. ljuí: Mimeógrafo, 2000.

DA COSTA, L. R Formação profissional em educação física, esporte e lazer no Brasil. Blumenau: Furb, 1999.

DAOLIO, J. Fenômeno social esporte na formação profissional em educação física, in: Revista da Educação Física/UEM 9 (1) p. 11-115, 1998.

FARIAS JÚNIOR, A. G. Perspectivas na formação profissional em educação física. In: MOREIRA, W. Educação física \& esporte: perspectivas para o século XXI. Campinas, SP: Papirus, 1993.

Movimento, Porto Alegre, v. 10, n. 1, p. 213-229, janeiro/abril de 2004 
FENSTERSEIFER, P. E. Conhecimento, epistemologia e intervenção. In: GOELLNER, S. V. Educação física/ciências do esporte: conhecimento e intervenção. Florianópolis: Colégio Brasileiro de Ciências do Esporte, 1999.

FERREIRA, M G. Metodologia de ensino do basquetebol no curso de formação de professores de educação física: Um relato de experiência. In: Pensar a prática.(1) p. 107124, 1998.

GONZALEZ, F. J. As disciplinas esportivas na formação superior: o que aprender e ensinar? In: Revista Brasileira de Ciências do Esporte. Florianópolis, v. 21, n. 1, p. $585-$ 592,1999 .

GONZALEZ, F.J. Estrutura e dinâmica dos esportes: classificação. ljuí: Unijuí, 2001

GRAÇA, A. Conhecimento do professor de educação física,. In: BENTO, J.; GARCIA, R.; GRAÇA, A. Contexto da pedagogia do desporto. Porto: Livros Horizonte, 2000.

MELO, M. et ai. Repensando a formação profissional em educação física: o caso das disciplinas esportivas. In: RIBEIRO, I L. (Org.) VI Encontro Fluminense de Educação Física Escolar 2002, Niterói. Anais do VI Encontro Fluminense de Educação Física Escolar. Niterói: Universidade Federal Fluminense, Departamento de Educação Física e Desportos, 2002.

MOLINA NETO, V Uma experiência de ensino do futebol no currículo de licenciatura em Educação Física. Revista Movimento, Porto Alegre, ano 2 n. 2, 1995 p.29-37.

OLIVEIRA, A. A. B. de. Análise crítica do currículo das disciplinas do curso de educação física da Universidade Estadual de Maringá. In: Kinesis, v.5 n.2 p. 229-257, 1989.

PARLEBAS, R Elementos de sociologia dei deporte. Malaga: Junta de Andalucia/Universidade Internacional Del Deporte de Andalucia, 1988.

PARLEBAS, R Juego, deporte y sociedad: léxico de praxiología motriz. Barcelona: Paidotribo, 2001.

PIRES, G; NEVES, A. O trato com o conhecimento do esporte na formação em educação física: possibilidades para sua transformação didática. In: KUNZ, E. Didática da educação física. ljuí: Unijuí, 2002.

PIROLO, A. L. A disciplina de voleibol nos cursos de licenciatura em Educação Física do Paraná: Processo de conhecimento crítico-reflexivo? In: COSTA, V. L. M. Formação profissional universitária em educação física. Rio de Janeiro: Editora Central da Universidade Gama Filho, 1997.

SCAGLIA, A.J. O futebol que se aprende e o futebol que se ensina. Unicamp: Dissertação de mestrado, 1999.

Movimento, Porto Alegre, v. 10, n. 1, p. 213-229, janeiro/abril de 2004 
SCHÖN, D. A. Educando o profissional reflexivo: um novo design para o ensino e aprendizagem. Porto Alegre: Artes Médicas Sul, 2000.

TANI, Go. Vivências práticas no curso de graduação em Educação Física: necessidade, luxo ou perda de tempo? Conferência de abertura: VI Simpósio de Pesquisa em Educação Física. UFSC: Centro de Desporto, s/d :17-31.

TERRA, D.V. Ensino crítico-participativo das disciplinas técnico-desportivas nos cursos de Licenciatura em Educação Física: análise do impacto de um projeto de ensino no Handebol. In: COSTA, V. L. M. Formação profissional universitária em educação física. Rio de Janeiro: Editora Central da Universidade Gama Filho, 1997.

Movimento, Porto Alegre, v. 10, n. 1, p. 213-229, janeiro/abril de 2004 